\title{
Comparison of oral health-related quality of life of patients treated by palatal expanders with patients treated by fixed orthodontic appliances
}

This article was published in the following Dove Press journal:

Patient Preference and Adherence

31 March 2017

Number of times this article has been viewed

\author{
Mariana A Alghamdi' \\ Nada J Farsi ${ }^{2}$ \\ Ali H Hassan ${ }^{3}$ \\ 'Faculty of Dentistry, ${ }^{2}$ Department \\ of Dental Public Health, ${ }^{3}$ Department \\ of Orthodontics, Faculty of Dentistry, \\ King Abdulaziz University, Jeddah, \\ Kingdom of Saudi Arabia
}

Introduction and purpose: Wearing orthodontic appliances may negatively affect a patient's oral health-related quality of life (OHRQoL) physiologically, psychologically, and socially. Few studies have assessed the effect of palatal expanders on OHRQoL. The aim of this study was to evaluate the impact of palatal expanders on OHRQoL and to compare it with that of fixed orthodontic appliances.

Materials and methods: All adolescent and adult orthodontic patients who were undergoing treatment with fixed appliances or palatal expanders between July 2015 and January 2016 in King Abdulaziz University Orthodontc Dental Clinics, were recruited ( $n=399)$. The OHRQoL of each participant was assessed using the shortened Arabic version of the Oral Health Impact Profile-14 questionnaire. OHRQoL was compared between users of fixed appliances and users of palatal expanders; it was also compared after stratifying the patients by gender. Chi-squared and Fisher's exact tests were used, as indicated.

Results: Palatal expanders had significantly greater negative effects on chewing ability $(P \leq 0.01)$ and pronunciation $(P=0.048)$. However, fixed orthodontic appliances had significantly greater negative impacts on mouth aching ( $P=0.003)$, difficulty in relaxing $(P=0.01)$, irritability $(P=0.001)$, and embarrassment $(P \leq 0.01)$.

Conclusion: Palatal expanders had a significantly greater negative impact on some aspects of OHRQoL when compared with fixed orthodontic appliances in adolescents and young adults. Keywords: OHRQoL, OHIP, OHIP-14, fixed orthodontic treatment, palatal expander

\section{Introduction}

In past dental research, clinicians' assessments in measuring oral health-related quality of life (OHRQoL) have been more important than subjective patients' assessments regarding factors such as perceived functional status and psychological well-being. ${ }^{1}$ However, clinicians' assessments of oral health and perceptions of oral diseases are different from patients' perspectives and assessments. ${ }^{2,3}$ Recently, assessing patients' perceptions of their oral status and their impact on OHRQoL has been central to understanding patient needs in relation to the perceived treatment quality. ${ }^{4,5}$

The present concept of OHRQoL is the absence of negative effects of oral conditions on patients' social lives and self-confidence, which is not restricted to the absence of oral diseases and dysfunction. ${ }^{6}$ OHRQoL has been considered a valid parameter in the assessment of social and psychological impacts of orthodontic treatment on quality of life, ${ }^{7-9}$ which provides a greater understanding of the need for orthodontic treatment that may be limited to orthodontists' parameters and may be used to supplement the orthodontist's clinical findings. . $^{1,2}$
Correspondence: Ali H Hassan Department of Orthodontics, Faculty of Dentistry, King Abdulaziz University, PO Box 80209, Jeddah 21589, Kingdom of Saudi Arabia Tel +966503647336

Email aakbr@kau.edu.sa 
Several instruments were previously used for OHRQoL assessment in relation to orthodontic appliances, such as the Child Perception Questionnaire 11-14, ${ }^{10}$ the Child Oral Impact on Daily Performance, ${ }^{11}$ and the Child Oral Health Impact Profile (OHIP). ${ }^{12}$ As an OHRQoL measure, the OHIP is one of the most widely used instruments. ${ }^{7,12-14}$ The old form of the OHIP consists of 49 items divided into seven dimensions; its complexity makes it difficult to use in the clinic. Therefore, a short version of OHIP that consists of 14 items was developed, and it, includes valuable weights on psychological and behavioral outcomes. It is formulated to identify psychosocial impacts among individuals and groups, and meets the main standards for the measurement of OHRQoL. ${ }^{15,16}$

Fixed orthodontic appliances and palatal expanders are the most common types of orthodontic appliances used and have been shown to have several consequences including physical, economic, social, and psychological impacts. Several studies have been conducted to show the negative influences of fixed orthodontic appliances on self-perception and quality of life in adolescents and young adults and to relate them to lifestyle and the social environment. ${ }^{17-24}$ On the other hand, few studies have evaluated OHRQoL among palatal expander wearers. ${ }^{25,26}$ Although palatal expanders are frequently indicated as a treatment for a constricted maxilla, which is caused by a growth deficiency of the maxilla during the craniofacial developmental period, they result in a transverse discrepancy between the maxilla and mandibular base. ${ }^{27}$ Because of the position and structure of these appliances, it is assumed that palatal expanders could have a negative impact on OHRQoL, and as mentioned earlier, limited research has been performed with an emphasis on the impact of palatal expanders on OHRQoL. The comparison of the OHRQoL impacts between fixed and expander users is under studied. Therefore, the aim of this study is to assess the impacts of palatal expanders on OHRQoL and compare them with the impacts of fixed orthodontic appliances.

\section{Materials and methods Study design and participants}

A cross-sectional study was conducted to assess the OHRQoL of patients undergoing orthodontic treatment with fixed or palatal expander appliances. All patients attending King Abdulaziz University, Faculty of Dentistry, Orthodontic Saudi Board Clinics between July 2015 and January 2016 were recruited. Adolescent and adult healthy patients aged 15-35 years who had been undergoing treatment for at least 6 months with either of palatal expanders (namely Hyrax,
Haas, and quad helix) or labial fixed orthodontic appliances were included in the study ( $n=399)$. The exclusion criteria were patients with any systemic diseases or physical limitation, craniofacial anomalies such as a cleft lip and palate, untreated dental caries, and poor periodontal health status as indicated by a Community Periodontal Index score of $>3 .{ }^{28}$ This was to prevent possible confounding effects of those conditions on the participant's quality of life. Patients who had completed orthodontic treatment were also excluded, as they might not be able to recall previous events as well as those undergoing active treatment.

\section{Data collection}

A list of eligible patients was obtained and they were approached while they were in the orthodontic clinic. Each patient was asked to fill out the questionnaire independently to prevent any possible influence from accompanying family members. OHRQoL was assessed using the validated Arabic version of OHIP-14 questionnaire, ${ }^{29-32}$ which consists of two items for each of the seven subscales in the source instrument (functional limitation, physical pain, psychological discomfort, physical disability, psychological disability, social disability, and handicap). Each patient was asked about the frequency that he or she experienced an impact on 14 daily activities. The items were the following: had problems pronouncing words, felt that the sense of taste had worsened, had painful aching in the mouth, found it uncomfortable to eat any food, had been self-conscious, felt tense, had an unsatisfactory diet, had to interrupt meals, found it difficult to relax, had been a bit embarrassed, had been irritable with other people, had difficulty performing useful jobs, felt that life, in general, was less satisfactory, and had been totally unable to function. Items are scored on an ordinal scale depending on the patient's responses, which included five options: "never," "hardly ever," "occasionally," "fairly often," and "very often." The following sociodemographic information was also collected: age, gender, nationality, and educational level.

Ethical approval was obtained from the Biomedical Ethics Research Committee of King Abdulaziz University, Jeddah, Saudi Arabia. Verbal consent was obtained from all participants during recruitment. The aim of the study was explained to the participants, and they were assured of the confidentiality of the collected information. Only those who gave verbal consent were included in the study.

\section{Statistical analysis}

The OHRQoL variables were dichotomized. For each of the 14 questions, responses of "occasionally," "fairly often," and 
"very often" were considered to represent negative impacts on OHRQoL. Responses of "never" and "hardly ever" were considered to denote no impact on OHRQoL. OHRQoL was compared between subjects using palatal expanders and those using fixed appliances; it was also assessed after stratifying the participants by gender. Chi-squared tests or Fisher's exact tests were used as indicated. $P$-value $<0.05$ was considered statistically significant. The statistical analysis was conducted using Stata version 13.0 (StataCorp LP, College Station, TX, USA). A post hoc power analysis was performed using G*Power 3.1. ${ }^{33}$ For the chi-squared test, assuming an observation of a small effect size (0.2) in a sample of 399 , achieves a power of $97.9 \%$ at a significance level of 0.05 .

\section{Results}

Table 1 presents the demographic characteristics of the study participants. The mean age of the participants was 19 years, and $61 \%$ were female. The majority of the participants had a high school degree or less $(69 \%)$, whereas $31 \%$ had a higher educational level. Subjects with fixed appliances were older on average than those with palatal expanders. Sixty percent of the female subjects and of the Saudi subjects wore fixed appliances.

Table 2 shows the OHIP-14 scores in relation to orthodontic treatment type. Fixed appliance users were more affected by mouth aching $(P=0.003)$ and difficulty in relaxing $(P=0.01)$ and had more irritability $(P=0.001)$ and embarrassment $(P<0.01)$ compared with subjects using palatal expanders. On the other hand, patients treated with palatal expanders reported more difficulty in chewing hard food $(P<0.01)$ and speech problems $(P=0.048)$ than subjects

Table I Sociodemographic characteristics of the participants

\begin{tabular}{|c|c|c|c|c|}
\hline Variable & $\begin{array}{l}\text { All } \\
\text { patients } \\
\text { n (\%) }\end{array}$ & $\begin{array}{l}\text { Fixed } \\
\text { appliance } \\
\mathbf{n}(\%) \\
\mathrm{n}=\mathbf{2 2 0}\end{array}$ & $\begin{array}{l}\begin{array}{l}\text { Palatal } \\
\text { expander }\end{array} \\
n(\%) \\
n=179\end{array}$ & $P$-value \\
\hline $\begin{array}{l}\text { Age, mean (SD), } \\
\text { years }\end{array}$ & $18.8(5.1)$ & 19.38 (4.95) & $18(0.39)$ & 0.007 \\
\hline Sex & & & & 0.018 \\
\hline Male & 155 (38.85) & 74 (47.74) & $81(52.26)$ & \\
\hline Female & $244(61.15)$ & I 46 (59.84) & $98(40.16)$ & \\
\hline Nationality & & & & 0.022 \\
\hline Saudi & $188(47.12)$ & 115 (6I.17) & 73 (38.83) & \\
\hline Non-Saudi & $211(52.88)$ & 105 (49.76) & $106(50.24)$ & \\
\hline Education level & & & & 0.075 \\
\hline $\begin{array}{l}\text { High school } \\
\text { and below }\end{array}$ & $276(69.17)$ & 144 (52.17) & 132 (47.83) & \\
\hline $\begin{array}{l}\text { Higher than } \\
\text { high school }\end{array}$ & $123(30.83)$ & 76 (6I.79) & $47(38.21)$ & \\
\hline
\end{tabular}

Abbreviation: SD, standard deviation.
Table 2 OHIP-I4 scores in relation to orthodontic treatment type

\begin{tabular}{|c|c|c|}
\hline OHIP-I4 & Fixed & Expander \\
\hline daily activity & n (\%) & n (\%) \\
\hline & $n=\mathbf{2 2 0}$ & $n=179$ \\
\hline
\end{tabular}

Functional limitation

Had problems pronouncing word

$\begin{array}{lll}\text { Impact } & 90(49.72) & 91(50.20) \\ \text { No impact } & 130(59.63) & 88(40.37)\end{array}$

Felt that the sense of taste worsened Impact $\quad 96(52.17) \quad 88(47.83)$

No impact $\quad 124(57.67) \quad 91$ (42.33)

Physical pain

Had painful aching in the mouth

$\begin{array}{lll}\text { Impact } & 125(62.50) & 75(37.50) \\ \text { No impact } & 95(47.74) & 104(52.26)\end{array}$

Found it uncomfortable to eat any food

$\begin{array}{llll}\text { Impact } & 60(38.7 I) & 95(6 I .29) & <0.0 \text { I** } \\ \text { No impact } & 160(65.57) & 84(34.43) & \end{array}$

\section{Psychological discomfort}

$\mathrm{Had}$ been self-conscious

Impact $\quad 4$ (44.44)

No impact $\quad 216(55.38)$

$5(55.56)$

$174(44.62)$

Felt tense

Impact

No impact

$220(55.14)$

$179(44.86)$

\section{Physical disability}

Had an unsatisfactory diet

$\begin{array}{lll}\text { Impact } & 2(40.00) & 3(60.00) \\ \text { No impact } & 218(55.33) & 176(44.6)\end{array}$

Had to interrupt meals

Impact $\quad 4(50.00)$

No impact $216(55.24)$

$0.514^{* *}$

Psychological disability

Found it difficult to relax

Impact $\quad 8(100.00) \quad 0(0)$

No impact $\quad 212(54.36) \quad 178(45.64)$

Had been a bit embarrassed

Impact $\quad 40(80.00) \quad 10(20.00)$

No impact $\quad 180(51.58) \quad 169(48.42)$

$0.661^{*}$

$1.000 *$

$4(50.00)$

$175(44.76)$

Social disability

Had been irritable with other people

Impact $\quad 80(67.80) \quad 38(32.20)$

No impact $\quad 140(49.82) \quad$ I4I (50.18)

Had difficulty doing useful jobs

Impact

No impact $220(55.14)$

$179(44.86)$

\section{Handicap}

Felt that life in general was less satisfactory

$$
\begin{array}{lll}
\text { Impact } & 5(83.33) & \text { I (16.67) }
\end{array}
$$$$
\text { No impact } \quad 215(54.7 \mathrm{I}) \quad 178(45.29)
$$

Had been totally unable to function

Impact $\quad 96(51.89) \quad 89(48.11)$

No impact $\quad 124(57.94) \quad 90(42.06)$

$0.010 *$

$<0.0$ l**

$<0.0$ l**

Notes: *Fisher's exact test was used. **Chi-squared test was used.

Abbreviation: OHIP, Oral Health Impact Profile. 
Table 3 Baseline characteristics of study participants stratified by sex

\begin{tabular}{|c|c|c|c|c|c|c|}
\hline \multirow[t]{2}{*}{ Variable } & \multicolumn{3}{|l|}{ Males } & \multicolumn{3}{|l|}{ Females } \\
\hline & $\begin{array}{l}\text { Fixed appliance } \\
n=74 \\
n(\%)\end{array}$ & $\begin{array}{l}\text { Palatal expander } \\
n=8 \text { I } \\
n(\%)\end{array}$ & $P$-value & $\begin{array}{l}\text { Fixed appliance } \\
n=\mid 46 \\
n(\%)\end{array}$ & $\begin{array}{l}\text { Palatal expander } \\
\mathrm{n}=98 \\
\mathrm{n}(\%)\end{array}$ & $P$-value \\
\hline Age, mean (SD), years & $19.78(5.03)$ & $17.72(4.94)$ & 0.011 & $19.18(4.92)$ & $18.23(5.44)$ & 0.161 \\
\hline Nationality & & & & & & 0.021 \\
\hline Saudi & $44(52.38)$ & $40(47.62)$ & 0.209 & 7I (68.27) & $33(31.73)$ & \\
\hline Non-Saudi & $30(42.25)$ & $4 \mid(57.75)$ & & $75(53.57)$ & $65(46.43)$ & \\
\hline Education level & & & & & & 0.384 \\
\hline High school and below & $49(43.75)$ & $63(56.25)$ & 0.108 & $95(57.93)$ & $69(42.07)$ & \\
\hline Higher than high school & $25(58.14)$ & $18(4 \mid .86)$ & & $5 \mathrm{I}(63.75)$ & $29(36.25)$ & \\
\hline
\end{tabular}

Abbreviation: SD, standard deviation.

with fixed appliances. There was no difference in OHRQoL between palatal expanders and fixed appliances with regard to the other items.

As illustrated in Table 3, among male participants, fixed appliance wearers were older than palatal expander users at 20 and 18 years of age on average, respectively $(P=0.011)$. However, no significant age difference was observed among the female participants. Among the female subjects, more Saudis wore fixed appliances than palatal expanders $(P=0.021)$ compared with subjects of other nationalities. The educational levels of the participants using fixed and palatal expander appliances were not significantly different among both the sexes.

Table 4 demonstrates OHRQoL among palatal expander and fixed appliance users stratified by sex. For both sexes, chewing ability was significantly more affected by palatal expander use than by fixed appliance use $(P<0.01)$. Both irritability and embarrassment were more impacted by fixed appliances than palatal expanders in both male subjects ( $P=0.029$ and 0.003 , respectively) and female subjects ( $P=0.024$ and 0.016 , respectively). Speech problems were greater among palatal expander users than fixed appliance users only among female subjects $(P<0.01)$. In contrast, among male subjects, fixed appliance users experienced a greater impact from mouth aching $(P=0.003)$. No difference was observed between female fixed orthodontic appliance and palatal expander patients with regard to mouth aching.

\section{Discussion}

The OHRQoL assessment is a highly recommended component of oral health research; it is used to develop oral health prevention and treatment programs. ${ }^{1}$ Recently, patient-based measures have been a greater area of interest among orthodontists to evaluate OHRQoL. ${ }^{34}$ However, there is limited existing knowledge regarding the effect of palatal expanders on OHRQoL, even though wearing such an appliance may affect physical, emotional, and psychological aspects of life. Therefore, the present study was performed to assess the impact of palatal expanders on OHRQoL among adolescents and adults who were treated using this appliance and compare the findings with patients who wore fixed orthodontic appliances. It is the first study assessing OHRQoL among patients wearing palatal expanders in Saudi Arabia.

In this study, wearing fixed orthodontic appliances showed a significantly negative impact on OHRQoL. This is in agreement with the work of Scheurer et al and others. ${ }^{17-24}$ Mouth aching was one of the parameters most negatively affected by wearing a fixed appliance. It has been confirmed by many studies that fixed orthodontic appliances have a negative influence on mouth aching. ${ }^{17-23}$ Moreover, a study revealed that patients wearing fixed appliances experienced more pain than those wearing removable orthodontic appliances (Invisalign, San Jose, CA, USA). ${ }^{21}$

Among fixed appliance wearers, more male subjects experienced pain compared with those wearing palatal expanders. The reason for this finding is not clear, but a possible explanation could be related to age. Male subjects who wore fixed orthodontic appliances were significantly older than those who wore palatal expanders, although this was not the case for the female patients. Previous studies proposed that adult patients had greater pain perception than younger patients during orthodontic treatment. ${ }^{17,19}$ Furthermore, Mandall et al revealed that adolescent patients could tolerate dental appliances more easily than older patients. ${ }^{22}$ However, this finding disagrees with de Oliveira and Sheiham's result, which found that women experienced more mouth aching than men. ${ }^{9}$

Our study also found that there were greater disturbances in relaxation among fixed orthodontic appliance wearers compared with those wearing palatal expanders. This is 
Table 4 Impact on daily activities in relation to sex and orthodontic treatment needs

\begin{tabular}{|c|c|c|c|c|c|c|}
\hline \multirow[t]{2}{*}{ OHIP-I 4 item } & \multicolumn{3}{|l|}{ Males } & \multicolumn{3}{|l|}{ Females } \\
\hline & $\begin{array}{l}\text { Fixed } \\
\text { appliance } \\
\mathrm{n}(\%), \mathrm{n}=\mathbf{7 4}\end{array}$ & $\begin{array}{l}\text { Palatal } \\
\text { expander } \\
n(\%), n=8 \text { I }\end{array}$ & $P$-value & $\begin{array}{l}\text { Fixed } \\
\text { appliance } \\
n(\%), n=146\end{array}$ & $\begin{array}{l}\text { Palatal } \\
\text { expander } \\
n(\%), n=98\end{array}$ & $P$-value \\
\hline Had problems pronouncing words & & & 0.513 & & & $<0.01$ ** \\
\hline Impact & $34(50.75)$ & $33(49.25)$ & & $56(49.12)$ & $58(50.88)$ & \\
\hline No impact & $40(45.45)$ & $48(54.55)$ & & $90(69.23)$ & $40(30.77)$ & \\
\hline Felt that the sense of taste worsened & & & 0.60 & & & $0.066 * *$ \\
\hline Impact & $36(50.00)$ & $36(50.00)$ & & $60(53.57)$ & $52(46.43)$ & \\
\hline No impact & $38(45.78)$ & $45(54.22)$ & & $86(65.15)$ & $46(34.85)$ & \\
\hline Had painful aching in the mouth & & & 0.003 & & & $0.158 * *$ \\
\hline Impact & $46(59.74)$ & $31(40.26)$ & & $79(64.23)$ & $44(35.77)$ & \\
\hline No impact & $28(35.90)$ & $50(64.10)$ & & $67(55.37)$ & $54(44.63)$ & \\
\hline Found it uncomfortable to eat any food & & & 0.001 & & & $<0.01 * *$ \\
\hline Impact & $22(32.84)$ & $45(67.16)$ & & $38(43.18)$ & $50(56.82)$ & \\
\hline No impact & $52(59.09)$ & 36 (40.9I) & & $108(69.23)$ & 48 (30.77) & \\
\hline Had been self-conscious & & & $1.000 *$ & & & $0.687^{*}$ \\
\hline Impact & I (33.33) & $2(66.67)$ & & $3(50.00)$ & $3(50.00)$ & \\
\hline No impact & $73(48.03)$ & $79(51.97)$ & & $143(60.08)$ & $95(39.92)$ & \\
\hline \multicolumn{7}{|l|}{ Felt tense } \\
\hline Impact & - & - & - & - & - & - \\
\hline No impact & $74(47.74)$ & 81 (52.26) & & $146(59.84)$ & $98(40.16)$ & \\
\hline Had an unsatisfactory diet & & & $0.498^{*}$ & & & $1.000 *$ \\
\hline Impact & - & $2(100.00)$ & & $2(66.67)$ & I (33.33) & \\
\hline No impact & $74(48.37)$ & $79(51.63)$ & & 144 (59.75) & $97(40.25)$ & \\
\hline Had to interrupt meals & & & $1.00 *$ & & & $0.687^{*}$ \\
\hline Impact & I $(50.00)$ & I (50.00) & & $3(50.00)$ & $3(50.00)$ & \\
\hline No impact & $73(47.7 I)$ & $80(52.29)$ & & $143(60.08)$ & $95(39.92)$ & \\
\hline Found it difficult to relax & & & $0.106 *$ & & & $0.160 *$ \\
\hline Impact & $3(100.00)$ & $0(0)$ & & $5(100.00)$ & 0 & \\
\hline No impact & 7I (46.7I) & 81 (53.29) & & |4| (59.24) & 97 (40.76) & \\
\hline Had been a bit embarrassed & & & $0.003^{*}$ & & & $0.016 * *$ \\
\hline Impact & $16(80.00)$ & $4(20.00)$ & & $24(80.00)$ & $6(20.00)$ & \\
\hline No impact & $58(42.96)$ & $77(57.04)$ & & $122(57.01)$ & 92 (42.99) & \\
\hline Had been irritable with other people & & & 0.029 & & & $0.024 * *$ \\
\hline Impact & $24(63.16)$ & $14(36.84)$ & & $56(70.00)$ & $24(30.00)$ & \\
\hline No impact & $50(42.74)$ & $67(57.26)$ & & $90(54.88)$ & $74(45.12)$ & \\
\hline \multicolumn{7}{|l|}{ Had difficulty doing useful jobs } \\
\hline Impact & - & - & - & - & - & - \\
\hline No impact & 74 (47.74) & 81 (52.26) & & $146(59.84)$ & $98(40.16)$ & \\
\hline Felt that life in general was less satisfactory & & & $0.193^{*}$ & & & $1.000 *$ \\
\hline Impact & $4(80.00)$ & I (20.00) & & $\mathrm{I}(100.00)$ & 0 & \\
\hline No impact & $70(46.67)$ & $80(53.33)$ & & $145(59.67)$ & $98(40.33)$ & \\
\hline Had been totally unable to function & & & 0.153 & & & 0.636 ** \\
\hline Impact & $29(4 \mid .43)$ & $4 \mathrm{I}(58.57)$ & & $67(58.26)$ & $48(4 I .74)$ & \\
\hline No impact & $45(52.94)$ & $40(47.06)$ & & 79 (6I.24) & $50(38.76)$ & \\
\hline
\end{tabular}

Notes: *Fisher's exact test was used. **Chi-squared test was used.

Abbreviation: OHIP, Oral Health Impact Profile.

consistent with several studies, which reported that sleep disturbances might be increased by wearing fixed orthodontic appliances. ${ }^{17,18}$

In addition, fixed orthodontic appliance wearers had been more embarrassed and irritable with other people than the comparison group, regardless of sex, because these types of orthodontic appliances are more noticeable to others than the expanders. This agrees with studies that revealed that fixed orthodontic appliances had significant negative impacts on patients' emotional and social well-being. ${ }^{22,23}$

This study indicated that the functions most affected by palatal expanders were eating and speaking in both sexes, except that speaking impacted female subjects more than male subjects. The association observed between wearing palatal expanders and pronunciation problems might be due to the expander's position, which interferes with the palate 
and makes word articulation more difficult. However, other studies reported a significant association between wearing fixed orthodontic appliances and pronunciation problems, ${ }^{18,24}$ which may be because their studies only investigated the impact of fixed orthodontic appliances on OHRQoL, but not in comparison with palatal expanders.

When the analyses were stratified by sex, a negative impact on pronunciation among expander users was evident only among female subjects, as mentioned previously. The reason for this finding is not clear. However, De Felippe et al reported that expander wearers had problems with speech regardless of sex. ${ }^{25}$ The significant association between difficulty in chewing hard food and wearing palatal expander appliances could perhaps be explained by the close relationship between chewing functions and the palate; given the position of the palatal expander, chewing function could be more greatly impaired among its users.

The potential effects on OHRQoL should be considered when choosing the type of appliance for each patient. Providing more information on the negative consequences of wearing an orthodontic appliance and their impacts on patients' physical, psychological, and social lives, might improve the patient's tolerance and increase their cooperation during treatment. Furthermore, these results may help orthodontists by providing insight into OHRQoL among these patients, to understand their expectations, and improve the quality of orthodontic care.

The Arabic version of OHIP that was used has been tested in convenience samples of the general population and in patients with specific oral conditions. Moreover, its reliability, validity, responsiveness, and internal consistency were confirmed. ${ }^{29-32}$ All eligible participants during the study period agreed to participate, which limited selection bias.

Some methodologic limitations must be considered. First, participants were recruited from one clinic, thus they do not represent the entire adolescent and young adult population with varying levels of orthodontic treatment, which may have different impacts on OHRQoL. Second, the participants were in different stages of treatment, which may have affected their responses toward the impacts of the appliances. However, several studies that assessed the impact of orthodontic appliances on OHRQoL at the beginning of orthodontic treatment reported that the negative impact of orthodontic appliances decreased over time. ${ }^{18-23}$ Lastly, the type of palatal expander was not considered in the study. Different types could affect OHRQoL differently. We were not able to assess this because if the subjects were stratified by expander type, there would have been very few subjects in each expander group to allow for meaningful analysis. Further studies to assess the OHRQoL of patients with different types of palatal expanders are warranted.

\section{Conclusion}

The results highlight the importance of evaluating OHRQoL among orthodontic patients, which determines the extent of the impact of having either a palatal expander, or a fixed orthodontic appliance on their lives. These factors could aid orthodontists in selecting treatment approaches with taking their effect on OHRQoL into consideration.

\section{Author contributions}

MAA collected the data, analyzed the results, and wrote the manuscript. NJF conducted the statistical analyses, contributed to writing the manuscript, and supervised MAA throughout writing the manuscript. AHH developed the idea of the research, designed the study, analyzed the results, and edited the manuscript.

\section{Disclosure}

The authors report no conflicts of interest in this work.

\section{References}

1. Cunningham SJ, Hunt NP. Quality of life and its importance in orthodontics. J Orthod. 2001;28(2):152-158.

2. Ahmed B, Gilthorpe MS, Bedi R. Agreement between normative and perceived orthodontic need amongst deprived multiethnic school children in London. Clin Orthod Res. 2001;4(2):65-71.

3. Hunt O, Hepper P, Johnston C, Stevenson M, Burden D. The aesthetic component of the index of orthodontic treatment need validated against lay opinion. Eur J Orthod. 2002;24(1):53-59.

4. Bedi R, Gulati N, McGrath C. A study of satisfaction with dental services among adults in the United Kingdom. Br Dent J. 2005;198(7): 433-437.

5. McGrath C, Bedi R. The value and use of 'quality of life' measures in the primary dental care setting. Prim Dent Care. 1999;6(2):53-57.

6. Locker D. Concept of oral health, disease and the quality of life. In: Slade GD, editor. Measuring Oral Health and Quality of Life. Chapel Hill, NC: University of North Carolina; 1997:11-23.

7. Hassan AH, Amin Hel-S. Association of orthodontic treatment needs and oral health-related quality of life in young adults. Am J Orthod Dentofacial Orthop. 2010;137(1):42-47.

8. Hassan AH, Hassan MH, Linjawi AI. Association of orthodontic treatment needs and oral health-related quality of life in Saudi children seeking orthodontic treatment. Patient Prefer Adherence. 2014;8: $1571-1579$

9. de Oliveira CM, Sheiham A. Orthodontic treatment and its impact on oral health-related quality of life in Brazilian adolescents. J Orthod. 2004; 31(1):20-27.

10. Bellot-Arcís C, Montiel-Company JM, Almerich-Silla JM. Psychosocial impact of malocclusion in Spanish adolescents. Korean J Orthod. 2013; 43(4):193-200.

11. Basavaraj P, Sunil MK, Nagarajappa R, Ashish S, Ramesh G. Correlation between oral health and Child-OIDP index in 12- and 15-year-old children from Modinagar, India. Asia Pac J Public Health. 2014;26(4):390-400. 
12. Reissmann DR, John MT, Sagheri D, Sierwald I. Diagnostic accuracy of parents' ratings of their child's oral health-related quality of life. Qual Life Res. 2016 Epub Oct 14.

13. Slade GD, Spencer AJ. Development and evaluation of the Oral Health Impact Profile. Community Dent Health. 1994;11(1):3-11.

14. Slade GD. Assessing change in quality of life using the Oral Health Impact Profile. Community Dent Oral Epidemiol. 1998;26(1):52-61.

15. Slade GD. Derivation and validation of a short-form Oral Health Impact Profile. Community Dent Oral Epidemiol. 1997;25(4):284-290.

16. Locker D, Matear D, Stephens M, Lawrence H, Payne B. Comparison of the GOHAI and OHIP-14 as measures of the oral health-related quality of life of the elderly. Community Dent Oral Epidemiol. 2001; 29(5):373-381.

17. Scheurer PA, Firestone AR, Bürgin WB. Perception of pain as a result of orthodontic treatment with fixed appliances. Eur J Orthod. 1996;18(4): 349-357.

18. Mansor N, Saub R, Othman SA. Changes in the oral health-related quality of life $24 \mathrm{~h}$ following insertion of fixed orthodontic appliances. J Orthod Sci. 2012;1(4):98-102.

19. Jones M, Chan C. The pain and discomfort experienced during orthodontic treatment: a randomized controlled clinical trial of two initial aligning arch wires. Am J Orthod Dentofacial Orthop. 1992;102(4):373-381.

20. Sergl HG, Klages U, Zentner A. Pain and discomfort during orthodontic treatment: causative factors and effects on compliance. Am J Orthod Dentofacial Orthop. 1998;114(6):684-691.

21. Miller KB, McGorray SP, Womack R, et al. A comparison of treatment impacts between Invisalign aligner and fixed appliance therapy during the first week of treatment. Am J Orthod Dentofacial Orthop. 2007;131(3):302.e1-e9.

22. Mandall NA, Vine S, Hulland R, Worthington HV. The impact of fixed orthodontic appliances on daily life. Community Dent Heal. 2006; 23(2):69-74.

23. Zhang M, McGrath C, Hägg U. Patients' expectations and experiences of fixed orthodontic appliance therapy. Impact on quality of life. Angle Orthod. 2007;77(2):318-322.
24. Paley JS, Cisneros GJ, Nicolay OF, LeBlanc EM. Effects of fixed labial orthodontic appliances on speech sound production. Angle Orthod. 2016;86(3):462-467.

25. De Felippe NL, Da Silveira AC, Viana G, Smith B. Influence of palatal expanders on oral comfort, speech, and mastication. Am J Orthod Dentofacial Orthop. 2010;137(1):48-53.

26. Haas AJ. The treatment of maxillary deficiency by opening the midpalatal suture. Angle Orthod. 1965;35:200-217.

27. Perillo L, Isola G, Esercizio D, Iovane M, Triolo G, Matarese G. Differences in craniofacial characteristics in Southern Italian children from Naples: a retrospective study by cephalometric analysis. Eur $J$ Paediatr Dent. 2013;14(3):195-198.

28. World Health Organization. WHO Basic Oral Health Survey. 4th ed. Geneva, Switzerland: World Health Organization; 1997.

29. Al-Jundi MA, Szentpétery A, John MT. An Arabic version of the Oral Health Impact Profile: translation and psychometric properties. Int Dent J. 2007;57(2):84-92.

30. Al Habashneh R, Khader YS, Salameh S. Use of the Arabic version of Oral Health Impact Profile-14 to evaluate the impact of periodontal disease on oral health-related quality of life among Jordanian adults. J Oral Sci. 2012;54(1):113-120.

31. Khalifa N, Allen PF, Abu-bakr NH, Abdel-Rahman ME. Psychometric properties and performance of the Oral Health Impact Profile (OHIP14s-ar) among Sudanese adults. J Oral Sci. 2013;55(2):123-132.

32. Allen PF, Locker D. Do item weights matter? An assessment using the Oral Health Impact Profile. Community Dent Health. 1997;14(3): 133-138.

33. Faul F, Erdfelder E, Buchner A, Lang AG. Statistical power analyses using $\mathrm{G}^{*}$ Power 3.1: tests for correlation and regression analyses. Behav Res Methods. 2009;41(4):1149-1160.

34. Tsakos G, Gherunpong S, Sheiham A. Can oral health-related quality of life measures substitute for normative needs assessments in 11 to 12-year-old children? J Public Health Dent. 2006;66(4):263-268.
Patient Preference and Adherence

\section{Publish your work in this journal}

Patient Preference and Adherence is an international, peer-reviewed, open access journal that focuses on the growing importance of patient preference and adherence throughout the therapeutic continuum. Patient satisfaction, acceptability, quality of life, compliance, persistence and their role in developing new therapeutic modalities and compounds to optimize

\section{Dovepress}

clinical outcomes for existing disease states are major areas of interest for the journal. This journal has been accepted for indexing on PubMed Central. The manuscript management system is completely online and includes a very quick and fair peer-review system, which is all easy to use. Visit http://www. dovepress.com/testimonials.php to read real quotes from published authors. 